\title{
THE INFLUENCE OF CARBOHYDRATE ON THE ORIGIN OF SYMPTOMS AND THE ONSET OF DEATH IN THIAMINE DEFICIENT PIGEONS
}

\author{
by \\ M. GRUBER \\ Laboratory for Physiological Chemistry, The University, Utrecht (Netherlands)
}

As is well known the so-called "vitamin $B_{1}$ sparing action of fat" denotes the delay of the occurrence of deficiency symptoms and death in animals on a thiamine free diet, when carbohydrate is replaced by fat. In former experiments it could be shown that the accelerated appearance of these phenomena in animals receiving increasing amounts of carbohydrate was caused by more rapid exhaustion of the thiamine pyrophosphate content of the tissues ${ }^{1}$. However the question was still open whether, besides this depleting action, administration of carbohydrate would also have a second effect on the level of thiamine pyrophosphate in the tissues at which symptoms and death by thiamine deficiency would then occur, as has been suggested by YuDKIN ${ }^{2}$. In order to investigate the possible existence of such a second effect of carbohydrate on the thiamine deficient animal the following experiment was carried out.

Two groups of pigeons were daily given by forced feeding the following thiamine-free foods supplemented with synthetic vitamins and other essential factors ${ }^{3}$ : Group A, $2 \mathrm{~g}$ casein and $\mathrm{I} 8 \mathrm{~g}$ sucrose; Group B, $2 \mathrm{~g}$ casein and $8 \mathrm{~g}$ refined soy-bean oil. Immediately after death by thiamine deficiency the thiamine pyrophosphate content was determined in several organs. The results are summarized in Table I.

TABLE I

TPP CONTENTS ( $\mu \mathrm{g} / \mathrm{g}$ TISSUE) OF THE ORGANS OF PIGEONS DEAD FROM THIAMINE DEFICIENCY

Group A: received carbohydrate

Group B: received no carbohydrate

\begin{tabular}{|c|c|c|c|c|c|}
\hline \multirow[b]{2}{*}{ Organ } & \multicolumn{2}{|c|}{ Group $A$} & \multicolumn{2}{|c|}{ Group $B$} & \multirow{2}{*}{$\begin{array}{l}P \text {-value of } \\
\text { difference }\end{array}$} \\
\hline & $\begin{array}{l}\text { Number of } \\
\text { animals }\end{array}$ & Mean & $\begin{array}{c}\text { Number of } \\
\text { animals }\end{array}$ & Mean & \\
\hline Liver & 35 & I.08 & 36 & I. 58 & $<0.001$ \\
\hline Heart & 35 & I.OO & 36 & 1.38 & $<0.001$ \\
\hline \multicolumn{6}{|l|}{ Breast } \\
\hline muscle & 35 & 2.79 & $3^{6}$ & I. 74 & $<0.001$ \\
\hline Cerebrum & 34 & 1.26 & 36 & $0.8 \mathrm{i}$ & $<0.001$ \\
\hline
\end{tabular}

The figures clearly show that there is a definite difference in the effect of administration of carbohydrate on the thiamine pyrophosphate level at death between liver and heart on the one hand and breast muscle (pectoralis major) and cerebrum on the other. We presume that death occurs when the thiamine pyrophosphate content in some centre attains the lethal level. Whether death occurred by the failure of different centres in each group or whether it is one and the same centre which is fatally affected cannot be decided. In the latter case it may be assumed that the lethal level in this organ is the same, whether the carbohydrate or the fat diet is given. We believe that there is no reason to assume any toxic effect of carbohydrate on thiamine deficient animals as has often been presumed.

This work forms part of investigations on the metabolism and physiological function of thiamine carried out by H. G. K. Westenbrink and collaborators. Full details and discussions are being published4.

\section{REFERENCES}

1 M. Gruber, Natuve, I66 (1950) I66.

2 J. Yudkin, Biochem. J., 48 (I95 I) 608.

3 M. Gruber, Acla Physiol. Pharmacol. Neerl., 2 (r952) 4 I I.

${ }^{4}$ M. Gruber, Biochim. Biophys. Acta, in the press. 